\title{
AC 2012-4284: TEACHING BY DESIGN: PREPARING K-12 TEACHERS TO USE DESIGN ACROSS THE CURRICULUM
}

\section{Dr. Louis Nadelson, Boise State University}

Louis S. Nadelson is an Associate Professor in the College of Education at Boise State University. His research interests include STEM teaching and learning, faculty development, in-service and pre-service teacher professional development, program evaluation, and multidisciplinary research. He has published research ranging from faculty professional development to the impact of inquiry on STEM learning. Nadelson earned a B.S. degree in biological and physics science from Colorado State University, a B.A. with concentrations in computing, mathematics, and physics from the Evergreen State University, a secondary teaching certificate from University of Puget Sound, an M.Ed. in instructional technology leadership from Western Washington University, and a Ph.D. (research-based, not theoretical) in educational psychology from the University of Nevada, Las Vegas.

Anne Louise Seifert, Idaho National Laboratory

Jill K. Hettinger, Boise State University

(c)American Society for Engineering Education, 2012 


\title{
Teaching by Design: Preparing K-12 Teachers to Use Design across the Curriculum
}

\begin{abstract}
Engineering design holds great potential as a STEM instructional approach. By capitalizing on the design process teachers can enhance student engagement, motivation, application of knowledge, and self assessment; elements essential for deep learning in STEM. Yet, many K-12 educators are not familiar with the structure, elements, and process of engineering design. Their unfamiliarity indicates a need to address K-12 teacher knowledge of engineering design to prepare them to use the process for instruction. We answered this call by making engineering design a theme and focus of a residential four-day summer institute for K-12 teachers. Through a combination of presentations, hands-on activities and examples of profession engineering applications, we provided $250 \mathrm{~K}-12$ educators with foundational knowledge of the design process. Our pre to post-institute measures revealed significant increases in their knowledge of design and increases in their ability to communicate the similarities and/or differences between scientific inquiry and engineering design. Implications and directions for further research are discussed.
\end{abstract}

\section{Introduction}

Education in science, technology, engineering, and mathematics (STEM) is fundamental to the goals of solving a myriad of international issues including meeting food, energy, health, and environment needs. Achieving these goals requires a populace educated in STEM. Key to public knowledge in STEM is the development of highly capable and inspirational K-12 teachers prepared to teach STEM. Using the extant literature, our experience, developments in STEM education, and the needs conveyed by the K-12 teacher community we identified a number of essential cognitive, affective, and pedagogical variables. These essential variables were then used to refine our i-STEM summer institute. The i-STEM institute is an ongoing teacher development summer academy designed to enhance the STEM teaching capacity of teachers of grades K-12.

The i-STEM is a multifaceted STEM initiative that includes an extensive K-12 teacher professional development program. The development program focuses on enhancing teacher capacity to implement best instructional practices, scientific inquiry, and engineering design within the context of highly engaging learning activities that teach STEM content. We are in the second year of the i-STEM professional development program and are continuing to improve the program through research and collaboration. The strength of our K-12 teacher professional development program comes from the joint influence of perspectives from education and STEM industries.

The primary focus of our report is a response to the dearth of literature reporting on K-12 teachers understanding of engineering design, and their subsequent abilities to conceptualize design in their process of instruction. Our professional development program is unique because we took a holistic perspective in addressing the STEM education needs of K-12 teachers including content knowledge, pedagogy, STEM careers, assessment, scientific inquiry, engineering design, and best practices. Further, our assessment of the program provides a unique 
contribution to the on-going exploration of how K-12 teachers develop an understanding of the processes used by STEM professionals and an awareness of unique skills needed to compete and succeed. Also, unique to our study is the nature of the data collection, using both quantitative and qualitative data, to assess participants' knowledge of engineering design and the size of the sample, over $100 \mathrm{~K}-12$ teachers participated in our project.

The purpose of this report is to share our research findings related to teacher understanding of the engineering design process before and after professional development. Before we present our findings we will explore the relevant literature. Following our presentation of results we will discuss the implications and provide suggestions for future research on K-12 teacher STEM professional development. We conclude with study limitations and how our findings contribute to the larger context of enhancing K-12 teacher STEM education capacity.

\section{Engineering Design in the K-12 Curriculum}

Design is the process by which engineers develop and optimize solutions ${ }^{1}$. Engineering design has been adopted in various forms in K-12 curriculum ${ }^{2,3,4,5,6,7,8}$. Although models of engineering design can vary in content and emphasis of components, there are elements that tend to be common to nearly all general engineering design configurations ${ }^{1}$. These common elements include: identifying a problem or forming a goal, recognizing the criteria and constraints associated with the problem or goals, brainstorming and exploring potential solutions, constructing a prototype, and evaluating the results. As the National Academy of Engineering and National Research Council ${ }^{1}$ acknowledge, design is not a linear process. Elements of the process are revisited when needed and if the project dictates, as optimization can require multiple iterations. Based on the work of NAE and $\mathrm{NRC}^{1}$ we developed a model that condenses this process into five elements that represent the fundamental aspects of design (see Table 1). Our intention was to simplify the design process to make it more accessible participants, with the goal of increasing the teachers' preparation to teach the processes of engineering design and engineering content. In addition, the basic elements of engineering design can be used as a way to develop and improve STEM curriculum, as a focus of learning activities, and the associated instructional method, as well as, increase student motivation and engagement in learning. 
Table 1. Essential Elements of the Design Process used in Instruction and the Associated Processes

\begin{tabular}{|c|c|c|c|c|c|}
\hline & \multicolumn{5}{|c|}{ Design Element } \\
\hline & $\begin{array}{c}\text { Problem or } \\
\text { Goal } \\
\text { Statement }\end{array}$ & $\begin{array}{l}\text { Criteria and } \\
\text { Constraints }\end{array}$ & $\begin{array}{c}\text { Generate Ideas } \\
\text { and Select } \\
\text { Solution }\end{array}$ & $\begin{array}{l}\text { Process Used } \\
\text { to Build the } \\
\text { Product }\end{array}$ & $\begin{array}{l}\text { Present Results } \\
\text { and Evaluate }\end{array}$ \\
\hline $\begin{array}{l}\text { Description of } \\
\text { the Associated } \\
\text { Process(s) }\end{array}$ & $\begin{array}{l}\text { The problem to } \\
\text { be solved/or } \\
\text { goal is } \\
\text { identified and } \\
\text { explained }\end{array}$ & $\begin{array}{l}\text { - Criteria to } \\
\text { which the } \\
\text { solution must } \\
\text { conform, and } \\
\text { the } \\
\text { specifications } \\
\text { for the product } \\
\text { are listed } \\
\text { - The } \\
\text { constraints, } \\
\text { limitations, or } \\
\text { bounds for the } \\
\text { product are } \\
\text { recognized }\end{array}$ & 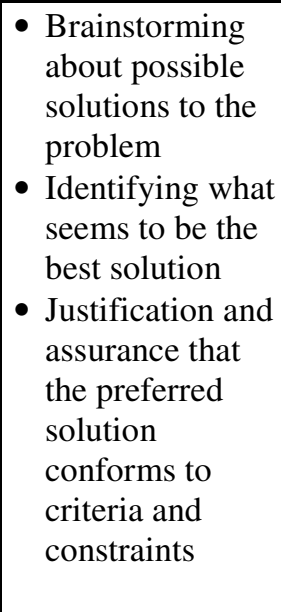 & $\begin{array}{l}\text { - A solution is } \\
\text { prototyped } \\
\text { - A solution is } \\
\text { selected and a } \\
\text { product is } \\
\text { constructed }\end{array}$ & $\begin{array}{l}\text { - The final } \\
\text { product is } \\
\text { presented to } \\
\text { others } \\
\text { - The product is } \\
\text { evaluated for } \\
\text { conformity to } \\
\text { criteria and } \\
\text { constraints and } \\
\text { effectiveness in } \\
\text { solving the } \\
\text { problem } \\
\text { - Modifications } \\
\text { inform the next } \\
\text { version }\end{array}$ \\
\hline
\end{tabular}

\section{Design as a Context for Learning}

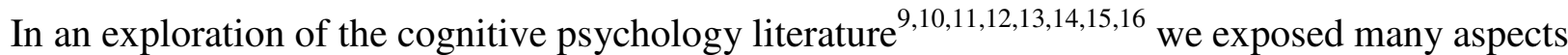
of learning that could be readily attended to using engineering design and design challenges as a curricular and instructional context. Since engineering design is about solving problems, many of which are problems with multiple possible solutions, is it ideal for promoting critical thinking and problem solving skills ${ }^{17}$. Engineering design is best approached when used as a multidisciplinary perspective, as an opportunity for integrating STEM content, as a way of increasing chances for students to apply their knowledge, and as a method to enhance student motivation and engagement in learning ${ }^{14}$. Additionally, learning opportunities grounded in engineering design challenges capitalizes on opportunities for learners to explore avenues of interest, develop novel solutions, and optimize solutions. These processes enhance learner engagement and development of mastery goal orientation and deep learning ${ }^{14}$. By the nature of the process, engineering design affords opportunities for learners to develop a range of skills that have been identified as essential to learning and meeting $21^{\text {st }}$ Century STEM careers needs.

The inherent link between engineering design challenges and implementing best instructional practices in STEM led us to make engineering design a primary focus for our four-day i-STEM summer institutes. We posit that enhanced teacher awareness, preparation, and utilization of 
engineering design challenges as a context for instruction and a curricular focus is likely to lead to higher levels of student learning and interest in engineering and STEM.

\section{Teacher Preparation to Teach Engineering Design}

As with other reform efforts that require the implementation of change, teacher adoption and adaptation of engineering design requires an investment in time, experience, and focused reflection $^{18}$. We posited that our expert modeling ${ }^{19}$ of the design process and explicit engagement of K-12 teachers in a range of design challenge activities would prepare them to integrate design into the curriculum and utilize design challenges as instructional contexts. Assuming that the teachers' participating in our summer institute had no or minimal exposure to and knowledge of engineering design, we began by working with them to develop foundational knowledge of engineering design.

Most K-12 teacher preparation programs do not include coursework in engineering, leaving a gap in K-12 teacher preparation to teach engineering concepts and use design challenges in instruction $^{20}$. Further, most K-8 teacher preparation programs typically require their graduates to have completed only two semesters of math and two semesters of science, leaving these teachers with additional gaps in their preparation to teach math and science content ${ }^{21}$. A broad understanding of math and science is especially critical for elementary teachers who may be responsible for teaching a range of STEM topics and concepts ${ }^{22,23}$. The potential need to teach a broad range of STEM content and the predicted constrained preparation provide the justification for providing professional development for K-12 teachers focused on enhancing their preparation to teach engineering and connections to math and science. Further, the increasing presence of engineering in the K-12 curriculum ${ }^{1,24}$ provides the justification for also attending to reducing the K-12 teachers' fear of the unknown and increasing their capacity to teach engineering, particularly those teachers who are endorsed in STEM domains.

Teacher professional development in STEM can have both implicit and explicit goals influencing an assortment of teacher content, pedagogical, and affective variables ${ }^{25,26,27}$. The connection between teacher effectiveness, confidence, and efficacy ${ }^{28,29}$, as well as the connection between content knowledge and teacher effectiveness ${ }^{30,31,32}$, and the influence of teacher pedagogical knowledge on student learning ${ }^{33}$ provides warrant for attending to a wide range of variables in teacher professional development. We contend that PD focused on engineering design processes and challenges is ideal for attending to a range of STEM teaching and learning variables. Further, we contend that teacher professional development in STEM is most effectively done when pedagogical content knowledge instruction is integrated with exposure to STEM content. Thus, we embraced these ideas by modeling how to effectively teach engineering design by explicitly drawing attention toward the link between engineering content and the associated instruction.

Using the extant literature and our knowledge and experience with STEM professional development we structured our summer institute to attend to the teachers' knowledge and feelings about teaching STEM, and in particular their knowledge of engineering design, their engineering design pedagogical content knowledge, and their awareness of integrating engineering design challenges into the curriculum. For example, in our summer institute we 
emphasized the exploration of a wide range of topics such as comparing and contrasting the similarities and differences between engineering design and scientific inquiry and engaged the teachers in a series of engineering design challenge activities, e.g. marshmallow and spaghetti towers, paper rockets, and water bottle rockets. We utilized the design challenge activities as curricular and instructional models for teaching engineering design content and processes while stimulating conversations regarding the integration of design as a context for teaching and learning STEM.

\section{Methods}

The goal of our project was to increase the K-12 educators who participated in our summer institute knowledge of engineering design and use of design challenges as an instructional approach. We used the following research questions to guide our research:

- What level of understanding of the engineering design process did our K-12 educators hold and did it change due to the institute?

- How did our participants perceive the similarities and difference of engineering design and scientific inquiry pre and post institute?

We anticipated that the engineering design focus of our summer institute would enhance our participants understanding of the design process. Further, we anticipated the presentations and content explicitly presenting the similarities and differences of scientific inquiry and engineering design would results in substantial increases in our participants' understanding of the unique and shared elements of inquiry and design.

\section{Participants}

The 250 educators from around Idaho that participated in our summer institute voluntarily registered for the event. Our participants were on average $43.10(\mathrm{~S}=10.2)$ years old, had been teaching $13.80(S=9.00)$ years, had taken $4.36(S=1.70)$ college level science classes and an average of $3.93(S=1.65)$ college level mathematics classes. Females made up $76 \%$ of the participants and $85 \%$ were from rural or suburban communities. Teachers from K-5 or K-6 schools made up $32 \%$ of the participants with middle/junior high school teachers representing $36 \%$, and high school teachers representing $8 \%$, with the remaining $25.5 \%$ coming from $\mathrm{K}-8$, $\mathrm{K}-$ 12 , and alternative schools. The majority $(51 \%)$ of our participants majored in elementary education, and $15 \%$ had biology or life science endorsements, the remainder held degrees in various STEM related fields, including instructional technology and health education.

\section{Instruments}

Design Knowledge Process Test. To assess our participants' knowledge of engineering design we adapted and adopted items from an extant instrument, Design Process Knowledge Test, validated for undergraduate engineering majors ${ }^{34}$. The original instrument used a selected response format to assess engineering design knowledge across a range of related concepts. Because of the difference in our study population, K-12 teachers, we determined it necessary to 
assess the items in the instrument and select only those that were aligned with general knowledge of engineering design and remove idiosyncratic definitions or items specific to being an undergraduate engineering major. The resulting instrument contained 18 items such as, "Which of these is the best definition of engineering design?" "Which is not a benefit of preliminary design or prototype?" and alternatives that represented a range of possible views, from naïve or misconceived to informed. Our version of the instrument also included several items such as, "Successful design involves breaking a problem down into smaller problems" which required responses along a Likert type scale ranging from " 1 " which represented "Almost always true" to 5 which represented "Almost always false" and included "I don't know." The authors of the original instrument report a Cronbach's alpha of .84 indicating a good level of instrument reliability.

Assessment of STEM Teaching and Learning. To determine the participants' perceptions and thoughts about STEM teaching and learning we developed an free response survey with eight items. We wanted to collect data that would allow us to establish how our participants defined STEM literacy, receive administrative support to teach STEM, integrate STEM, assess students' STEM knowledge and awareness, and most salient to this study, how they perceived the similarities and differences between scientific inquiry and engineering design. The survey items were generated by a committee assembled to develop the i-STEM summer institute. The items were grounded in the extensive discussions of the potential barriers to teaching STEM and our professional development focus on engineering design. Items asked participants to respond to questions such as, "How do you define STEM literacy?" and "Describe what you consider to be best practices in STEM teaching." and "What are the similarities and differences between scientific inquiry and engineering design?" The participants were instructed to provide the detail necessary to fully understand their perspectives.

\section{Professional Development}

We structured our intensive four-day summer residential professional development institute to enhance STEM content and pedagogical knowledge of the K-12 teachers who volunteered to participate. The professional development (PD) consisted of approximately 40 hours of contact time with 20 of those of dedicated to content area strands, which were mini-courses developed around themes such as wind energy, robotics, flying, and mining. The strand providers were charged with integrating elements of engineering design in their curriculum and providing opportunities to explore the application of engineering design in various contexts. The contents of the 20 hour themed strands were dependent on proposals submitted by the individuals or organizations applying to be strand instructors, and were selected by the perceived potential to fulfill our established standards of quality and content. Once selected, the providers submitted: a syllabus, a list detailing the contents of a classroom "kit" consisting of up to $\$ 300$ of supplies needed to implement their curriculum that was distributed to each of the strand participants, and a pre/post test of content/subject knowledge covered in the strands. Each strand enrolled about 15-20 participants who met daily for approximately 5 hours evenly divided between morning and afternoon. During this time the participants explored the strand content through lab activities, hands-on instructional activities, field trips, and presentations. 
The balance of the 40 hours included presentations by keynote speakers who discussed and explored topics that included comparing engineering design to scientific inquiry, assessing learning of students engaged in design challenges, and how engineering design takes place in industry. Time was also spent on team building using design challenges as a context for collaboration. These activities included competitive building and testing of water and paper rockets. We included a presentation on cognitive psychology by an internationally known researcher and a presentation of the applications of engineering in weather balloon based research. Throughout the summer institute the engineering design theme was attended to explicitly and implicitly.

\section{Data Collection}

All data collection took place on-line using a web-based survey site. The participants were instructed to use the "same last five digits of any phone number" as a unique code for all surveys so that their responses could be tracked. Prior to the summer institute all participants were sent an e-mail requesting they complete the surveys before they arrived at the summer institute and the URL link to the surveys. We developed the surveys so that they had to be taken in sequence and concluded with a completion verification page which the participants were instructed to print and bring with them to the institute at registration to document they completed the pre-surveys. We had computers available at registration for those who had not completed the surveys to do so on-site prior to the start of the institute.

The participants were post-tested in a similar fashion. A link to the survey sites was sent to all participants with a request to complete the surveys within two weeks after the close of the summer institute. Over the next four weeks, reminders to complete the surveys were emailed out to the participants. We provided the extended timeline to complete the post-institute surveys to increase the likelihood that the participants took time to provide accurate and complete answers.

\section{Results}

Prior to conducting our analysis we calculated the reliability of our design knowledge process tests. Our analysis revealed a Cronbach's alpha of .72 which indicates a good level of reliability, yet reduced from the level obtained by the instrument authors. We speculate that the reduced reliability coefficient was due to the very limited knowledge of design by our participants increasing the potential for them to answer the items erratically, which negatively influences reliability values.

\section{Design Knowledge}

Our first research question asked, What level of understanding of the engineering design process did our K-12 educators hold and did it change due to the institute? To answer this question we examined the composite scores to our design knowledge process test. The analysis of the pretest composite scores revealed that prior to the institute our participants had an average correct of $10.55(S=3.27)$ out of the 18 possible. Although no specific scoring interpretation is provided by the authors of the instrument we suggest that the pre-institute score is commensurate with what might be considered to be the average public knowledge of design. 
Our analysis of our post-institute design knowledge process test scores revealed an average of $13.03(S=2.85)$, which is again out of a possible 18 . We interpreted the post-institute mean to be an indicator of above average level of knowledge of design, and approaching knowledge commensurate with an undergraduate engineering major early in his/her program of study.

To determine if there was a difference we conducted a paired samples t-test of the pre and postinstitute scores using the phone code to match the results. Once we conditioned our data and matched the scores based on the phone code our sample size was reduced to 165 . We had several participants who did not complete the post test and many participants who used different phone codes in the pre and post-institute assessments. Regardless, we progressed assuming that the 165 was representative of our 250 participants. Our paired samples t-test revealed $t(164)=$ $10.45, p<.01$, indicating a significant change in our participants design knowledge. The effect size for our analysis was $d=.80$, which is considered to be large. Interpreted, our participants' experienced a large gain in their knowledge of engineering design, increasing on average 2.5 points, or about .80 standard deviations.

\section{Similarities and Differences between Scientific Inquiry and Engineering Design}

Our second research question asked, How did our participants perceive the similarities and difference of engineering design and scientific inquiry pre and post institute? To answer this question we conducted a content analysis 35 of our participants' pre and post institute responses to our Assessment of STEM Teaching and Learning item, "What are the similarities and differences between scientific inquiry and engineering design?" We classified each of the participant's responses into one of four categories. The categories were "No knowledge of Similarities or Differences" "Similarities understood, Differences not understood or not identified" "Similarities not understood or not identified, Differences understood" and "Similarities understood, Differences understood." The categories with representative responses are presented in Table 1. The percentages of our participants' pre and post institute responses classified by category are displayed graphically in Figure 1. 
Table 1. Classification of our Participants Pre and Post Institute Responses to the Similarities and Differences between Inquiry and Design

Coding Examples

No knowledge of Similarities or Differences

"Unsure."

Similarities understood, Differences not understood or not identified

"Similarities - creative, open ended, require research Differences?"

Similarities not understood or not identified, Differences understood

Similarities understood, Differences understood

\begin{abstract}
"Inquiry allows students to dabble in science toward solving a myriad questions and problems; whereas engineering design focuses on the products that solve these explored problems."
\end{abstract}

"I think it's the numerous iterations that need to take place that make them similar. Initial plans sometimes don't work as intended. Students need to be able to analyze the data, intentionally make changes, and test to see if they get a better product. The biggest difference I think is that engineering design is specifically looking for a product. Scientific inquiry on the other hand can be product based, but also can be hypothesis/theory based with no outward product." 


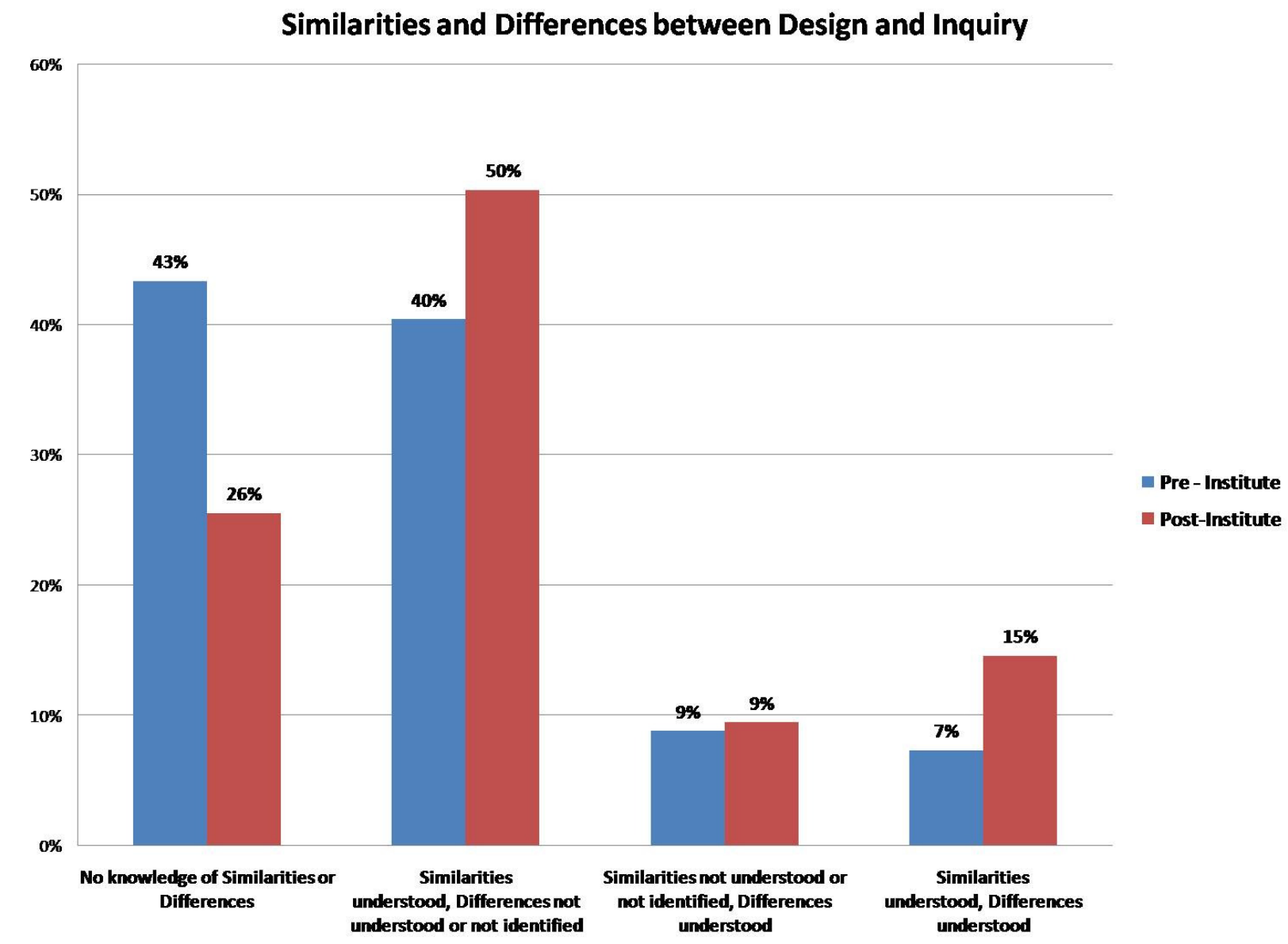

Figure 1. Pre and post-institute frequencies of participants' responses to our similarities and differences free response item.

Our analysis is descriptive in nature and not inferential, thus, the use of the term "notable" is not to be interpreted as being "statistically significant." Our analysis revealed that our participants' responses shifted from pre-test to post-test with a notable decline in the percentage of no knowledge of similarities or differences shifting from $43 \%$ in the pre-institute to $26 \%$ in the postinstitute. Accompanying the shift from no knowledge was a notable increase in the percentages of answers indicating a deeper understanding of the unique and shared aspects of design and inquiry. Our analysis revealed a notable increase in our participants' abilities to communicate the similarities of inquiry and design shifting from $40 \%$ of the responses in the pre-institute to $50 \%$ in the post institute. Further, we detected a shift of about $8 \%$ increase in the ability to communicate both the similarities and differences of inquiry and design (See Figure 1).

\section{Discussion}

In an effort to address the call for increase K-12 student preparation in STEM we created and implemented a four day residential professional development summer institute for K-12 educators. Although there is inconsistent support from the literature associating the influence of 
teacher subject knowledge and their capacity to influence student achievement ${ }^{36}$, we embraced the position of those researchers who have detected this relationship ${ }^{37,38,39,40}$. Further, we followed the recommendations of Yasar and colleagues ${ }^{41}$ who argue that it is essential to attend to teachers' knowledge of and attitudes toward engineering to prepare them to teach engineering. We contend that preparing educators to teach using engineering design requires developing their knowledge of using design challenges as an instructional approach. Understanding the process of design and teaching using design challenges provides educators with the pedagogical content knowledge associated with integrating engineering into multiple facets of STEM curriculum. We attempted to attend to aspects of teachers' STEM knowledge and understanding and use of engineering design in our summer institute.

Our results revealed that our participants experienced significant increases in their knowledge of the design process, indicating the engineering and design focused lessons, activities, and theme of our summer institute were effective for increasing the participants' design content knowledge. It is important to recall that only a small number of the 20 hour content sessions focused exclusively on engineering and design and only a portion of the general sessions were specific to engineering and design. Regardless, the institute underlying theme kept engineering and design in the forefront of the event and the hands-on activities (e.g. building the tallest free standing tower with spaghetti and marshmallows) provided concrete models for implementing design challenges. Further the hands-on activities provided a context for discussing design elements such as criteria, constraints, and optimization. Although it is likely that many K-12 teachers may have integrated similar design challenges in their instruction, our summer institute is likely to be their first formal instruction in the specific elements of engineering design linked to teaching using design challenges. Thus, our participants' were provided with the opportunity to engage in the processes of engineering design as well as discuss and internalize the design process. Thus, we significantly increased the participants' design knowledge and laid a foundation for further development of our participants' comfort and fluency teaching using an engineering design framework.

Our analysis of the participants' descriptions of the similarities and differences of scientific inquiry and engineering design revealed some notable shifts in their knowledge. However, we also found that $26 \%$ of post-institute responses indicated they had no knowledge of the similarities or differences between engineering design and scientific inquiry. Although disappointing, it may be possible that our participants were pressed for time when completing the post-test and simply did not want to spend the time to provide complete answers. It may be also be the participants still did not understand the similarities and differences between design and inquiry. The teachers could have been distracted during the summer institute and were not attentive enough to achieve the anticipated gains in understanding. Although aspects of scientific inquiry are common in K-12 instruction many teachers' may not be familiar with the specific terminology and elements of inquiry recognized by STEM education researchers. Thus, they may have felt that they had to have expert level knowledge and answers to adequately respond. The same may have been true of the educators' knowledge and perceptions of design. Gaining a deeper understanding of how teachers conceptualize inquiry and design and view their preparation to describe the similarities and differences is an excellent direction for future research. 
Our analysis revealed that our participants were more readily able to communicate the similarities of inquiry and design than the differences between the two processes. We speculate this occurred because the participants experienced a design activity that explicitly highlighted the similarities of design and inquiry while the differences were presented in a more didactic format. Further, the differences between scientific inquiry and design are arguably more subtle and philosophical whereas the similarities between the two are more explicit and pragmatic. Therefore, learning and communicating the differences between scientific inquiry and engineering design is more challenging. We did find an increase in the percentage of participants who could communicate both the similarities and differences between inquiry and design. We speculate that these participants likely had some understanding prior to the institute and their experience at our professional development institute increased their knowledge. How teachers develop their understanding of using design and inquiry in instruction, and how handson activities impact teacher understanding are likely to be important directions for future investigations.

\section{Limitations}

Our data was collected as self report and therefore is subject to the associated limitations. The lack of depth in some of the free response items does indicate that some of the participants simply did not want to put forth the time and effort necessary to answer the questions. Interviews, recorded verbal responses, or focus groups may be more effective at capturing more in depth responses.

The participants in our study were K-12 teachers, representing a range of subject areas and grade levels. Differences in answers based on experience were not recorded, as we were examining the data in aggregate and in the case of the free response data, descriptively. Nevertheless, given the general lack of integration of engineering in the K-12 curriculum we feel that the outcome is representative of K-12 teachers.

\section{Conclusion}

The purpose of our report was to share our research findings related to teacher understanding and intellectual growth in the engineering design process. Our research revealed that a relatively brief well crafted intervention can significantly impact K-12 educators' knowledge of engineering design. We also found that developing a deeper understanding of engineering design is likely to be a long term process, particularly when educators are tasked with comparing and contrasting engineering design with other complex processes such as scientific inquiry. Regardless, the alignment of engineering design with the variables associated with how people learn provides justification for continuing to explore and research how we can enhance K-12 educators' capacity to teach using engineering design challenges. 


\section{References}

[1] National Academy of Engineering and National Research Council: Committee on K-12 Engineering Education. (2009). Engineering in K-12 Education: Understanding the Status and Improving the Prospects. Washington, D.C., National Academies Press.

[2] Crismond, D. (2001). Learning and using science ideas when doing investigate-and-redesign tasks: A study of naive, novice, and expert designers doing constrained and scaffolded design work. Journal of Research in Science Teaching, 38(7), 791-820.

[3] Cunningham, C. (2009). Engineering Is Elementary. The Bridge, 30(3), 11-17.

[4] Hynes, M. \& dos Santos, A. (2007). Effective teacher professional development: Middle school engineering content. International Journal of Engineering Education, 23(1), 24-29.

[5] Lewis, T. (2006) Design and inquiry: Bases for an accommodation between science and technology education in the curriculum? Journal of Research in Science Teaching, 43(3), 255-281.

[6] National Aeronautics and Space Administration (n.d.) Elementary School Standards-Based Engineering Design Process.(n.d.). Retrieved from http://www.nasa.gov/audience/foreducators/ plantgrowth/reference Eng_Design_K4.htmlNASA

[7] Sadler, P. M., Coyle, H. P., \& Schwartz, M. (2000). Engineering competitions in the middle school classroom: Key elements in developing effective design challenges. The Journal of the Learning Sciences, 9(3), 299-327.

[8] The Works: A Hands-On Museum (2011). You are an engineer. Retrieved from: http://www.theworks.org/fb/teachers/engineering_design_process.html

[9] Anderson, L.W. \& Krathwohl (Eds.). (2001). A taxonomy for learning, teaching, and assessing: A revision of bloom's taxonomy of educational objectives. New York: Longman.[10] Bruning, R., Schraw, G. \& Ronning, R. (1999). Cognitive psychology and instruction (3rd ed.), Upper Saddle River, NJ: Prentice Hall.

[11] Csikszentmihalyi, M. (1997). Finding flow: The psychology of engagement with everyday life. New York: Basic Books.

[12] Eccles, J. S. \& Wigfield, A. (2002). Motivational beliefs, values, and goals. Annual Review of Psychology, $52,109-132$.

[13] Flavel, J. H. (1987). Speculations about the nature and development of metacognition. In F. E. Weinert \& R. H. Kluwe (Eds.) Metacognition, motivation, and understanding. . Hillsdale, NJ: Erlbaum.

[14] National Research Council. (1999). How people learn: Brain, mind, experience, and school. Washington, D.C.: National Academy Press.

[15] Schraw, G.\& Lehman, S. (2001). Situational interest: A review of the literature and directions for future research. Educational Psychology Review, 13, 23-52.

[16] Sternberg, R. J. \& Williams, W. M. (2010). Educational psychology. Upper Saddle River, NJ; Pearson.

[17] Kitchener, K. S. (1983). Cognition, metacognition, and epistemic cognition: A three-level model of cognitive processing. Human Development, 26(4), 222-232.

[18] Hall, G., \& Hord, S. (2006). Implementing change ( $2^{\text {nd }}$ ed.). Needham Heights, MA: Allyn and Bacon. 
[19] Collins, A., Brown, J.S., \& Newman. S. (1989). Cognitive apprenticeship: Teaching the craft of reading, writing, and mathematics.In L.B. Resnick (Ed.), Knowing, learning and instruction: Essays in honor of Robert Glaser. Hillsdale, NJ: Erlbaum, 1989.

[20] Kimmel, H., Carpinelli, J., Alexander, L. B., \& Rockland. R. (2006). Bringing engineering into K-12 schools: A problem looking for solutions? Proceeding of the American Society for Engineering Education Annual Conference and Exposition. Chicago, IL.

[21] Fulp, S. L. (2002). The status of elementary school science teaching. Retrieve from: http://www.horizonresearch.com/reports/2002/2000survey/elem_sci.php.

[22] Raymond, A. (1997). Inconsistency between a beginning elementary school teacher's mathematics beliefs and teaching practices. Journal for Research in Mathematics Education, 28, 550-576.

[23] Yilmaz-Tuzun, O. (2008). Preservice elementary teachers' beliefs about science teaching. Journal of Science Teacher Education, 19(2), 183-204.

[24] Gomex, A. G.(2002). Engineering, but how?" in Proceeding of the American Society for Engineering Education Annual Conference and Exposition. Albuquerque NM,

[25] Nadelson, L.S., Callahan, J, Pyke, P. Hay, A. \& Schrader, C. (2009). A Systemic Solution: Elementaryteacher preparation in STEM expertise and engineering awareness. Proceedings of the American Society for Engineering Education Annual Conference \& Exhibition, Austin, TX.

[26] Nadelson, L.S., Callahan, J, Pyke, P. Hay, A. \& Schrader, C. (2010). Teaching inquiry-based STEM in the elementary grades using manipulatives: A SySTEMic solution report. . Proceedings of the American Society for Engineering Education Annual Conference \& Exhibition, Louisville, KY.

[27] Nadelson, L. S., Pfiester, J., Callahan, J., Pyke, P., Hay, A. \& Emmet, M. (2011). Connecting science with engineering: Using inquiry and design in a teacher professional development course. Proceedings of the American Society of Engineering Education Annual Conference, Vancouver, BC.

[28] Appleton, K. (2003). How do beginning school teacher cope with science towards an understanding of science teaching practice. Journal for Research in Science Teaching, 33, 1-25.

[29] Shallcross, T., Spink, E., Stephenson, P., \& Warwick, P. (2002). How primary trainee teacher perceive the development of their own scientific knowledge: Links between confidence, content and competence? International Journal of Science Education, 24(12), 1293-1312.

[30] Ball, D. L. (1988). Research on teaching mathematics: Making subject matter knowledge part of the equation (Research Report No. 88-2). East Lansing, MI: National Center for Research on Teacher Learning, Michigan State University.

[31] Lederman, N.G., Gess-Newsome, J., \& Latz, M.S. (1994). The nature and development of preservice science teachers' conceptions of subject matter and pedagogy. Journal of Research in Science Teaching, 31, 129-146.

[32] Wilson, S., Floden, R., \& Ferrini-Mundy, J. (2001). Teacher preparation research: current knowledge, gaps, and recommendations. Washington, DC: Center for the Study of Teaching and Policy.

[33] Darling-Hammond, L. \& Bransford, J. (2005). Preparing teachers for a changing world: What teachers should learn and be able to do. San Francisco :Jossey-Bass. 
[34] Sims-Knight, J., Upchurch, R., \& Fortier, P. (2006). Design process knowledge test. Paper presented at the National STEM Assessment Conference, October 19-21, 2006. Washington, D.C.

[35] Miles, M. \& Huberman, M. (1984). Qualitative data analysis: A source book for new methods ( $2^{\text {nd }}$ Edition). Thousand Oaks, CA: Sage Publications.

[36] Darling-Hammond, L. \& Youngs, P. (2002). Defining "highly qualified teachers": What does "scientificallybased research" actually tell us? Educational Researcher, 31(9), 13-25.

[37] Ball, D. L., Lubienski, S., \& Mewborn, D. (2001). Research on teaching mathematics: The unsolved problem of teachers' mathematics knowledge. In V. Richardson (Ed.), Handbook of research on teaching, (4th ed) (pp. 433-456). New York: Macmillan.[38] Goldhaber, D. D. \& Brewer, D. J. (2000). Does teacher certification matter? High school teacher certification status and student achievement. Educational Evaluation and Policy Analysis, 22(2), 129-146.

[39] Monk, D. H. (1994). Subject area preparation of secondary mathematics and science teachers and student achievement. Economics of Education Review, 13(2), 125-145.

[40] Rowan, B., Chiang, F., \& Miller, R. J. (1997). Using research on employees' performance to study the effects of teachers on students' achievement. Sociology of Education, 70(4), 256-284.

[41] Yasar, S., Baker, D., Robinson-Kurpius, S., Krause, S., \& Roberts, C. (2006). Development of a survey to assess K-12 teachers' perceptions of engineers and familiarity with teaching design, engineering, and technology. Journal of Engineering Education, 95 (3), 205-16. 